\title{
Significance of normal septal motion in total anomalous pulmonary venous drainage
}

\author{
M F SHIU, M MILES, E D SILOVE \\ From the Department of Cardiology, Birmingham Children's Hospital, Birmingham
}

SUMMARY Paradoxical septal motion is considered to be a characteristic feature of total anomalous pulmonary venous drainage, reflecting the right ventricular volume overload in this condition. Patients with additional pulmonary venous obstruction have reduced pulmonary blood flow, and would be expected to show normal septal motion. We have studied the haemodynamic and echocardiographic findings in 21 patients with proven total anomalous pulmonary venous drainage and found paradoxical septal motion in only 11 instances. Paradoxical septal motion was present in all nine patients over the age of 1 month. Of the 12 neonates, 10 showed normal septal motion.

Patients with normal septal motion had clinical features of pulmonary venous obstruction, with significantly higher pulmonary artery pressures and lower pulmonary artery saturations than patients with paradoxical septal motion.

It is concluded that in total anomalous pulmonary venous drainage, septal motion reflects pulmonary blood flow, allowing separation of patients into those with or those without pulmonary venous obstruction.

Septal motion on the M-mode echocardiograms of children with total anomalous pulmonary venous drainage has been reported as typically paradoxical, ${ }^{1-4}$ reflecting the right ventricular volume overload in this condition. Normal septal motion, however, has been reported, particularly in very young infants. ${ }^{56}$ Since most other M-mode echocardiographic features of total anomalous pulmonary venous drainage are non-specific, ${ }^{34}$ we feel the diagnostic value of septal motion in these patients might be important. We reviewed the presenting echocardiographic and haemodynamic findings in 21 cases of proved total anomalous pulmonary venous drainage. Septal motion was classified and the clinical and haemodynamic features were compared between patients with normal septal motion and those with paradoxical septal motion. The effect of pulmonary venous obstruction on echocardiographic septal motion was noted.

\section{Patients and methods}

Between June 1975 and September 1980, 25 patients with total anomalous pulmonary venous drainage were diagnosed by cardiac catheterisation at the

Received for publication 5 February 198
Birmingham Children's Hospital. Twenty-one patients had preoperative echocardiograms of adequate standard and these formed the subjects of this study. All patients underwent operative correction and the site of drainage was verified at operation. The patients' age at presentation, weight, and relevant clinical, echocardiographic, and haemodynamic data are listed in the Table. Most of the children presenting under 1 month had central cyanosis and congestive heart failure. The older infants had features of a left-to-right shunt and failure to thrive, but none was clinically cyanosed. Two children over 1 year of age were asymptomatic.

\section{ECHOCARDIOGRAPHIC RECORDINGS}

Echocardiograms were obtained using an unfocused 3.5 or $\mathrm{MHz}$ transducer positioned at the second to fourth intercostal space. Recordings were made with a Smith-Kline echocardiograph interphased with a Honeywell strip chart recorder. Sweep recordings from the aortic root and left atrium to the mitral valve and apex of the left ventricle were made by the standard technique. Echocardiograms were analysed by one observer (MM) with no knowledge of the clinical or haemodynamic findings. Septal motion was analysed at mid-ventricular level when both leaflets of the mitral valve were present. Movement was 
Table Clinical, haemodynamic, and echocardiographic data in 21 patients with total anomalous pulmonary venous drainage

\begin{tabular}{|c|c|c|c|c|c|c|c|c|c|}
\hline No & Age & Weight (kg) & Cyanosis & $\begin{array}{l}\text { Pulmonary artery } \\
\text { pressure ( } \mathrm{mm} H \mathrm{~g} \text { ) }\end{array}$ & $\begin{array}{l}\text { Pulmonary } \\
\text { artery oxygen } \\
\text { saturation }\end{array}$ & $R V D d(\mathrm{~cm})$ & $\operatorname{LVDd}(\mathrm{cm})$ & $\begin{array}{l}\text { Interventricular } \\
\text { septal motion }\end{array}$ & Drainage site \\
\hline 1 & ld & $3 \cdot 42$ & + & $110 / 50(68)$ & 51 & 1.4 & 1.4 & Normal & Superior \\
\hline 2 & $2 d$ & $3 \cdot 20$ & + & $78 / 48(58)$ & 78 & 1.5 & $1 \cdot 1$ & Normal & Superior \\
\hline 3 & $4 d$ & $3 \cdot 24$ & - & $50 / 25(30)$ & 83 & 1.6 & $1 \cdot 3$ & Type B & Inferior \\
\hline 4 & $5 d$ & $3 \cdot 18$ & + & $76 / 40(60)$ & 85 & $1 \cdot 3$ & $1 \cdot 5$ & Normal & Superior \\
\hline 5 & $6 d$ & $2 \cdot 90$ & + & $62 / 28(46)$ & 75 & $1 \cdot 0$ & $1 \cdot 0$ & Normal & Superior \\
\hline 6 & $2 w k$ & $2 \cdot 05$ & - & $35 / 6^{\star}$ & 84 & $1 \cdot 4$ & $1 \cdot 5$ & Type B & $\mathrm{CS}$ \\
\hline 7 & $2 w k$ & $2 \cdot 84$ & + & $90 / 40(55)$ & 77 & 1.8 & 1.5 & Normal & Superior CS \\
\hline 8 & $2 w k$ & $3 \cdot 60$ & + & $65 / 40(50)$ & 75 & 1.6 & $1 \cdot 1$ & Normal & Inferior \\
\hline 9 & $3 w k$ & $3 \cdot 30$ & + & $100 / 50(70)$ & 62 & 1.6 & $1 \cdot 3$ & Normal & Superior \\
\hline 10 & $3 w k$ & $4 \cdot 20$ & + & $85 / 40(60)$ & 56 & 1.4 & $1 \cdot 3$ & Normal & Inferior \\
\hline 11 & $3 w \mathbf{k}$ & $2 \cdot 45$ & - & $90 / 40(55)$ & 65 & $1 \cdot 2$ & $1 \cdot 1$ & Normal & Inferior \\
\hline 12 & $4 w k$ & $3 \cdot 34$ & + & $110 / 30(55)$ & 79 & $2 \cdot 0$ & 1.0 & Normal & Superior \\
\hline 13 & $5 w k$ & $3 \cdot 27$ & + & $52 / 15(32)$ & 83 & 1.8 & 1.9 & Type A & CS \\
\hline 14 & 5 wk & $2 \cdot 79$ & - & $40 / 10(20)$ & 95 & 1.9 & $1 \cdot 2$ & Type B & Superior \\
\hline 15 & $8 w k$ & $4 \cdot 10$ & - & $39 / 14(20)$ & 87 & $2 \cdot 0$ & 1.4 & Type A & Superior \\
\hline 16 & 10wk & $2: 80$ & - & $32 / 18(22)$ & 95 & 1.8 & $1 \cdot 3$ & Type A & CS \\
\hline 17 & 3mth & $3 \cdot 12$ & - & $75 / 25(45)$ & 90 & $2 \cdot 0$ & $1 \cdot 1$ & Type B & CS \\
\hline 18 & 4mth & $4 \cdot 66$ & - & $45 / 8 \quad(22)$ & 92 & $2 \cdot 0$ & $1 \cdot 3$ & Type A & Superior \\
\hline 19 & $5 \mathrm{mth}$ & $5 \cdot 18$ & - & $85 / 30(55)$ & 97 & $2 \cdot 2$ & $1 \cdot 3$ & Type B & Superior \\
\hline 20 & $18 \mathrm{mth}$ & $10 \cdot 1$ & - & $69 / 40(48)$ & 93 & 3.5 & $2 \cdot 0$ & Type A & Cardiac \\
\hline 21 & $2 y$ & $9 \cdot 6$ & - & $25 / 11(19)$ & 93 & $2 \cdot 4$ & $2 \cdot 5$ & Type A & Superior \\
\hline
\end{tabular}

${ }^{\star}$ Right ventricular pressure in case 6. RVDd, right ventricular end-diastolic dimension, LVDd, left ventricular end-diastolic dimension. Drainage sites were all confirmed at time of surgical correction. CS, coronary sinus.

classified as normal, type A, or type B paradoxical (Fig. 1). Normal septal motion is posterior during systole. In type $A$, the ventricular septum moves anteriorly and in the same direction as the left ventricular posterior wall. In type B the ventricular septum moves little in either direction during systole. Right and left ventricular end-diastolic dimensions were measured at the time of the $R$ wave peak of the electrocardiogram as recommended by the American Association of Echocardiographers.

\section{HAEMODYNAMIC MEASUREMENTS}

Cardiac catheterisations were performed under local or general anaesthesia. Intracardiac pressures were measured with a Statham PG 25 E transducer via fluid filled catheters with mid thorax as zero reference.
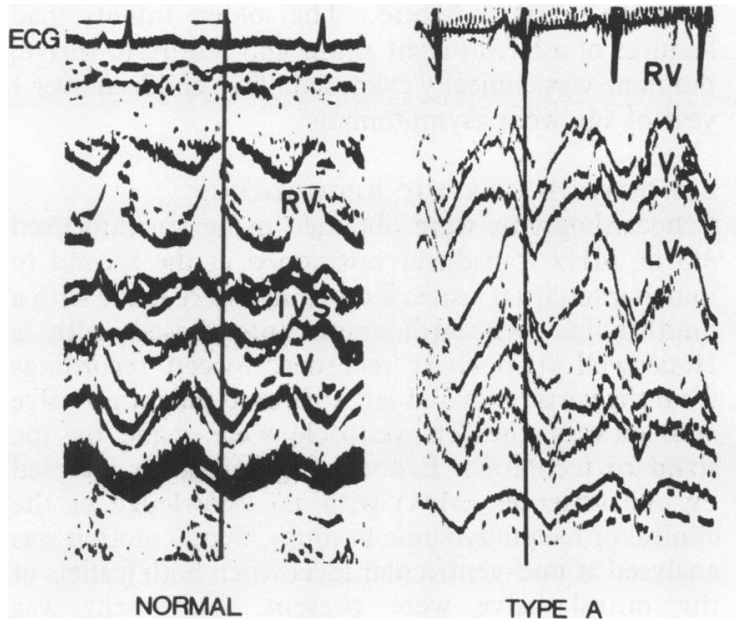

TYPE A

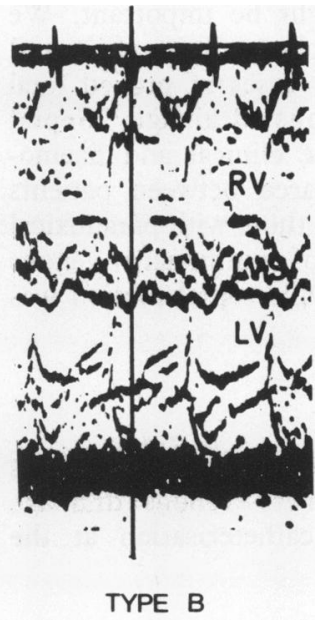

Fig. 1 Normal and type $A$ and type $B$ paradoxical septal motion in three patients with total anomalous pulmonary venous drainage. The vertical lines indicate the onset of ventricular systole. Normal systolic motion is posterior, type $A$ is anterior, and type $B$ is flat with no net anterior or posterior motion. 
Oxygen saturations were measured using a reflectometer (Kipp) and calibrated against an American Optical Oximeter.

\section{Results}

\section{ECHOCARDIOGRAPHIC FINDINGS Ventricular dimensions}

Right ventricular dimensions were abnormally large and left ventricular dimensions abnormally small in nearly all the patients (Fig. 2). Comparison between patients aged 1 day to 4 weeks and those between 5 weeks and 5 months showed that the former group had significantly smaller right ventricular dimensions $(1.48 \pm 27 \mathrm{~cm}$ compared with $1.9 \pm 0.24 \mathrm{~cm} ; \mathrm{p}<0.01)$. Left ventricular dimensions were not significantly different in the two groups.

\section{SEPTAL MOTION}

Paradoxical septal motion of either type A or type B was found in all nine patients aged over 1 month (Fig. 3). None but one of the youngest of these was clinically cyanosed, and no patients had the infradiaphragmatic type of drainage. Haemodynamic data of these patients are given in the next section.

Normal septal motion was found in 10 of 12 patients under 1 month of age (Fig. 4). All but one of the 10 had cyanosis as well as congestive heart failure. Two patients in this age group with type B paradoxical septal motion were not cyanosed (see Table).

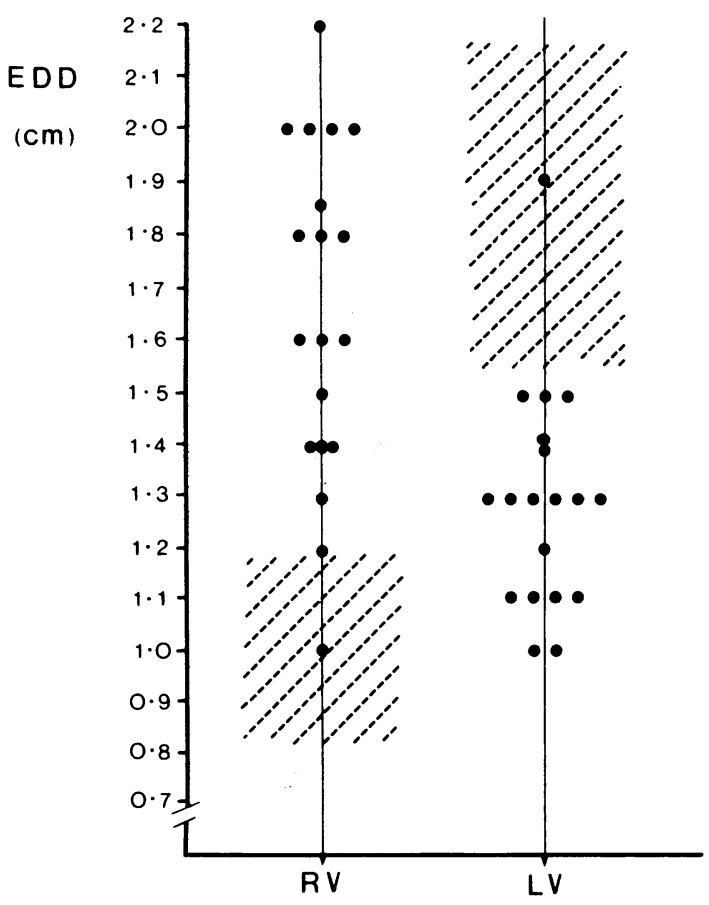

Fig. 2 Echocardiographic right and left ventricular enddiastolic dimensions (EDD) in 19 infants with total anomalous pulmonary venous drainage aged 1 day to 5 months. Shaded areas are normal ranges for the age group. Cases 20 and 21 are aged over 1 year and are not included.

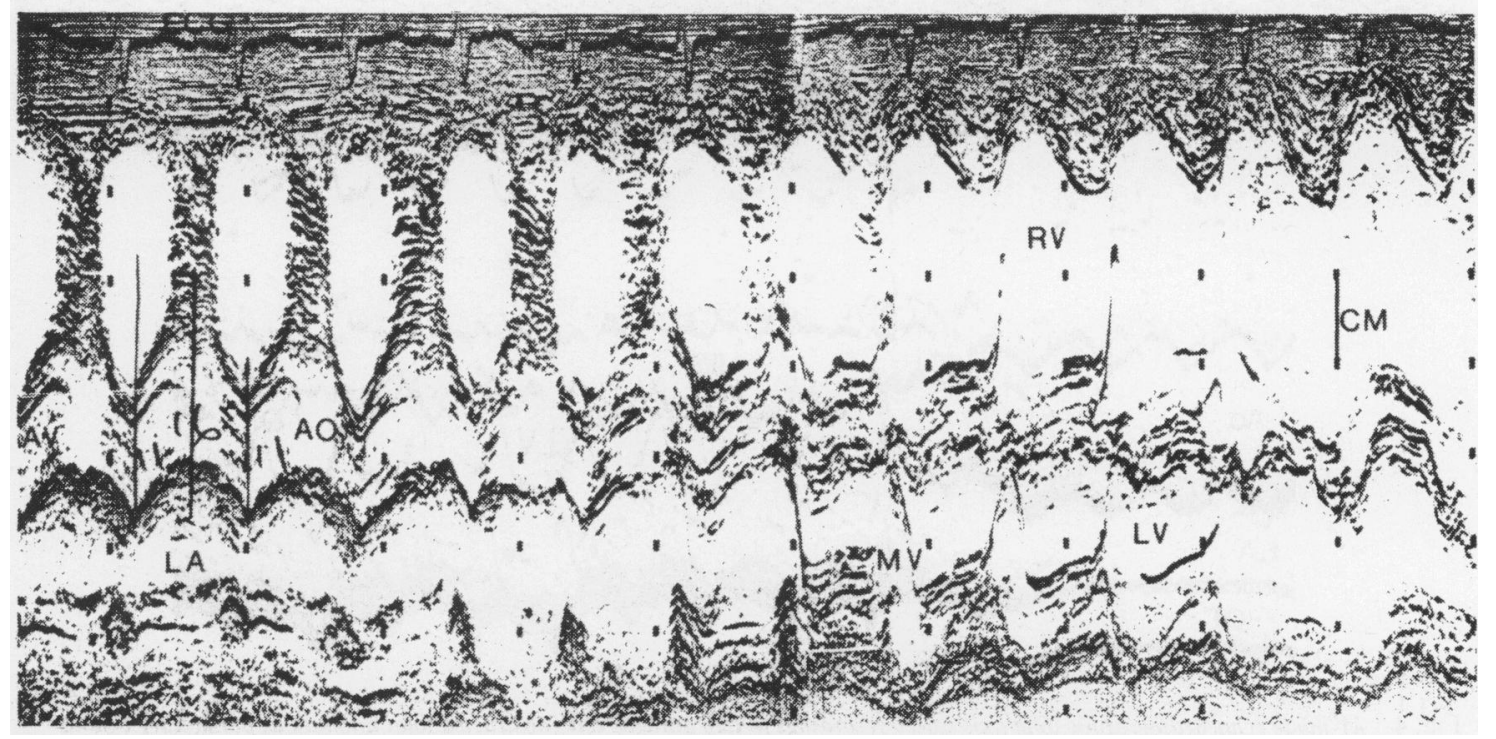

Fig. $3 M$-mode echocardiographic long axis sweep recording in a patient with total anomalous pulmonary venous drainage without venous obstruction (case 20 ) showing right ventricular enlargement and paradoxical septal motion. AO, aorta; LA, left atrium; RV, right ventricle; $L V$, left ventricle; $M V$, mitral valve. 
HAEMODYNAMICS

Systolic pulmonary artery pressure was significantly higher in the 10 patients with normal septal motion, being $86 \cdot 6 \pm 17 \mathrm{mmHg}$ as against $49 \cdot 7 \pm 19 \mathrm{mmHg}$ $(\mathrm{p}<0.001)$ in the 11 patients with paradoxical septal motion. Pulmonary artery saturation was significantly lower in the patients with normal septal motion, being $70.3 \pm 11 \%$ against $90 \pm 5 \cdot 1 \%(\mathrm{p}<0.001)$ in the remaining patients. The two neonates with paradoxical septal motion also had the lowest right heart pressures in that age group.

\section{Discussion}

Paradoxical septal motion is a characteristic echocardiographic feature of right ventricular volume
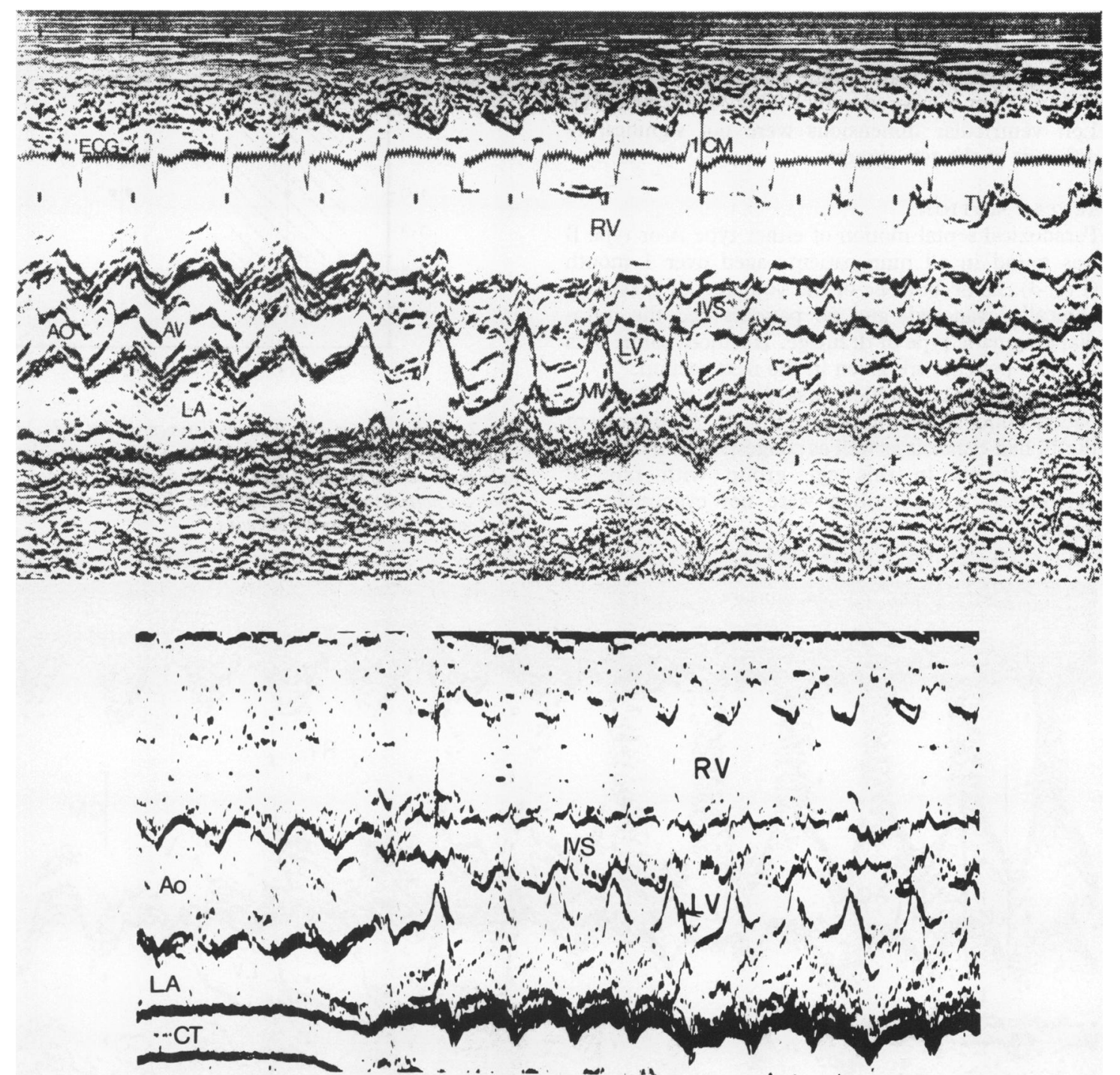

Fig. 4 M-mode echocardiographic long axis sweep recordings in two patients with obstructed total anomalous pulmonary venous drainage, cases 9 (top) and 12 (bottom), showing normal systolic motion of the interventricular septum (IVS). AV, aortic valve; TV, tricuspid valve; CT, echo free space behind left atrium probably representing the common venous trunk. Other abreviations as in Fig. 3. 
overload. It is therefore a predictable finding in patients with uncomplicated total anomalous pulmonary venous drainage, where pulmonary blood flow is high. When total anomalous pulmonary venous drainage is complicated by pulmonary venous obstruction and pulmonary hypertension, however, pulmonary blood flow is reduced. ${ }^{7}$ This has been given as the explanation for the occasional finding of normal septal motion in cases of proven total anomalous pulmonary venous drainage. ${ }^{6}$ The situation is analogous to patients with atrial septal defect and pulmonary hypertension. ${ }^{8}$

The present study shows that the majority of patients with total anomalous pulmonary venous drainage presenting before 1 month of age had normal septal motion, while older patients showed paradoxical septal motion of either type A or B. Clinical and haemodynamic findings indicate that patients with normal septal motion had pulmonary venous obstruction whereas the others did not. The prevalance of pulmonary venous obstruction in children presenting early is well recognised. ${ }^{7}$ This explains our finding of normal septal motion exclusively in the neonates. Pulmonary venous obstruction is also more likely in infradiaphragmatic drainage, and three out of four of our patients with this anatomy had normal septal motion as well as other features of obstruction.

The present series differs from published series on this subject in the high proportion of neonates. Our series is unselected and reflects the age range of patients presenting with this problem. Paquet and Gutgesell's series, in which all six patients had paradoxical septal motion, had no children under 4 months of age. ${ }^{1}$ Two other series ${ }^{34}$ reporting paradoxical septal motion in all of 12 patients both dealt exclusively with patients with coronary sinus drainage. Each series had two patients under 1 month of age. Pulmonary venous obstruction was not discussed but, considering the site of drainage and that pulmonary artery pressure in these patients did not exceed $60 \mathrm{mmHg}$, obstruction was probably not present. In contrast to these reports, normal septal motion was reported by Bozio and Davignon ${ }^{5}$ in two neonates aged 1 and 13 days and by Godman et al. ${ }^{6}$ in a $3 \frac{1}{2}$ week old infant. In a follow-up letter to their paper, Paquet and Gutgesell ${ }^{9}$ reported normal septal motion in two neonates.
The limitations of $M$-mode echocardiographic diagnosis of total anomalous pulmonary venous drainage are well known. ${ }^{34}$ Our results show that paradoxical septal motion is a reliable feature of uncomplicated total anomalous pulmonary venous drainage, but is of little value where pulmonary venous obstruction is a possibility. Increasingly, total anomalous pulmonary venous drainage is diagnosed by two-dimensional echocardiogram, as were the last three patients in this series. In these patients, $M$-mode echocardiographic assessment of septal motion gave additional information on the presence or absence of pulmonary venous obstruction.

\section{References}

1 Paquet $\mathrm{M}$, Gutgesell $\mathrm{H}$. Echocardiographic features of total anomalous pulmonary venous correction. Circulation 1975; 51: 599-605.

2 Glaser J, Whitman V, Liebman J. The differential diagnosis of total anomalous pulmonary venous drainage in infancy by echocardiography (abstract). Circulation 1972; 46, suppl II: 38.

3 Orsmond GS, Ruttenberg HB, Bessinger FB, Moller JH. Echocardiographic features of total anomalous pulmonary venous connection to the coronary sinus. Am f Cardiol 1978; 41: 597-601.

4 Aziz KU, Paul MH, Bharati S, Lev M, Shannon K. Echocardiographic features of total anomalous pulmonary venous drainage into the coronary sinus. Am $\mathcal{F}$ Cardiol 1978; 42: 108-13.

5 Bozio A, Davignon A. Interpreting the echocardiogram in TAPVC (letter). Circulation 1976; 53: 1041-2.

6 Godman MJ, Tham P, Kidd BSL. Echocardiography in the evaluation of the cyanotic newborn infant. Br Heart $\mathcal{F}$ 1974; 36: 154-66.

7 Gathman GE, Nadas AS. Total anomalous pulmonary venous connection: clinical and physiologic observations of 75 pediatric patients. Circulation 1970; 42: 143-54.

8 Diamond MA, Dillon JC, Haine CL, Chang S, Feigenbaum H. Echocardiographic features of atrial septal defect. Circulation 1971; 43: 129-35.

9 Paquet M, Gutgesell HP. Interpreting the echocardiogram in TAPVC (letter). Circulation 1976; 53: 1042.

Requests for reprints to Dr M F Shiu, Department of Cardiology, Queen Elizabeth Hospital, Birmingham B15 2TH. 